04

\title{
Линейная трансформация поляризационных мод в намотанных на катушку spun-световодах с сильным невозмущенным линейным двулучепреломлением. І. Нерезонансная трансформация.
}

\author{
(С) Г.Б. Малыкин ${ }^{1}$, В.И. Позднякова ${ }^{2}$ \\ ${ }^{1}$ Федеральный исследовательский центр Институт прикладной фризики РАН, \\ 603155 Нижний Новгород, Россия \\ ${ }^{2}$ Институт ффизики микроструктур РАН - фрилиал ФГБНУ „Федеральный исследовательский центр \\ Институт прикладной физики РАН“, \\ 603950 Нижний Новгород, Россия \\ e-mail: malykin@ufp.appl.sci_nnov.ru
}

Поступила в редакцию 18.09.2017 г.

Рассмотрена линейная трансформация ортогональных поляризационных мод в намотанных на катушку spun-световодах с сильным невозмущенным линейным двулучепреломлением, приводящая к возникновению зависимости от длины световода интегрального эллиптического двулучепреломления, эллиптичности и азимута большой оси эллипса, а также состояния поляризации излучения (СПИ). В процессе вытяжки из заготовки spun-световоды испытывают сильное механическое закручивание, которое при остывании „вмораживается“ в структуру световода. Поскольку значения локальных поляризационных параметров, намотанных на катушку spun-световодов, меняются по довольно сложному закону, то вычисления проводились с помощью численного моделирования параметров матриц Джонса. Используется то обстоятельство, что в сопровождающей кручение (винтовой) системе координат на достаточно коротком отрезке намотанного на катушку spun-световода, где скорость вращения осей его двулучепреломления постоянна, локальными нормальными поляризационными модами такого световода приближенно являются так называемые винтовые поляризационные моды В.Л. Гинзбурга (ВПМГ) - два взаимно ортогональных эллипса с противоположным направлением обхода, оси которых однонаправленно равномерно вращаются относительно неподвижной системы координат. Показано, что, несмотря на то что невозмущенное линейное двулучепреломление spun-световодов существенно превышает обусловленное намоткой на катушку линейное двулучепреломление, интегральное двулучепреломление протяженного отрезка такого световода по порядку величины совпадает с обусловленным намоткой на катушку линейным двулучепреломлением, а интегральные поляризационные моды асимптотически стремятся к циркулярным. Показано также, что значения циркулярного двулучепреломления скрученных одномодовых волокон, рассчитанные в невращающеейся и в сопровождающей кручение винтовой системах координат, существенно отличаются. Показано, что в процессе линейной трансформации локальных поляризационных мод возникают поляризационные явления, приводящие к небольшим квазигармоническим осцилляциям интегральных параметров двулучепреломления spun-световодов в зависимости от их длины, причем период этих осцилляций примерно равен половине эффективного периода поляризационных биений.

DOI: $10.21883 /$ OS.2018.03.45658.208-17

\section{1. Введение}

Линейная трансформация (или взаимодействие) волн - это широкий класс физических явлений, характеризующихся перераспределением волнового движения между различными нормальными (взаимно ортогональными) волнами, происходящим в результате изменения свойств среды в пространстве и (или) во времени под действием внешних факторов. В отличие от нелинейного взаимодействия волн, при котором пространственно-временно́е изменение свойств среды обусловлено самими взаимодействующими волнами [1-3], линейная трансформация волн не связана с нарушением принципа суперпозиции волновых полей. Систематические исследования в этой области были начаты в 50-х гг. прошлого века в связи с изучением распространения волн в ионосферной плазме, нерегу- лярных СВЧ- и акустических волноводах [1,2]. Отметим, что, несмотря на отсутствие зависимости параметров среды от амплитуды волн, в процессе линейной трансформации волн могут возникать поляризационные явления, связанные с нелинейностью определения поляризационных характеристик, проявляющихся в процессе распространения света в неравномерно скрученном оптическом волокне. Таким образом, указанная нелинейность возникает не по амплитуде электрического поля, а по состоянию поляризации излучения (СПИ). Причины этого явления будут рассмотрены ниже.

В 1979 г. фактически была рассмотрена линейная трансформация ортогональных поляризационных мод в равномерно скрученных одномодовых волоконных световодах (ОВС) с невозмущенным линейным двулучепреломлением [4]. В 1980-1981 гг. было показано, что незначительные кручения азимутов осей линейного дву- 
лучепреломления в ОВС приводят к связи ортогональных поляризационных мод $[5,6]$. Таким образом, в $[5,6]$ фактически с помощью метода малых возмущений была рассмотрена линейная трансформация ортогональных поляризационных мод в ОВС. В 1983 г. было проведено целенаправленное рассмотрение линейной трансформации ортогональных поляризационных мод от длины $\mathrm{OBC}$ для различных законов кручения азимутов осей линейного двулучепреломления [1,2]. Для ряда важных частных случаев в $[1,2]$ были получены точные или приближенные аналитические решения. В 1997 г. было показано, что основной причиной линейной трансформации ортогональных поляризационных мод на случайных неоднородностях в ОВС являются случайные кручения осей световода, возникающие в процессе его вытяжки из преформы вследствие крутильных колебаний еще не вполне застывшего волокна [7] (см. также $[8,9]$ ). Были также определены статистические характеристики поляризации света, связанные с рассматриваемыми случайными кручениями [7-9].

Несмотря на то что данный вопрос изучается около сорока лет, и ему посвящено весьма большое число журнальных статей и ряд монографий (соответствующие ссылки приводятся в обзорных частях $[8,9])$, задача о линейной трансформации ортогональных поляризационных мод в ОВС до сих пор окончательно не решена. Дело в том, что в подавляющем большинстве случаев основным элементом оптоволоконных датчиков различных физических параметров является ОВС, намотанный на катушку. В этом случае имеют место два типа линейного двулучепреломления ОВС: во-первых, невозмущенное линейное двулучепреломление, обусловленное внутренним поперечным механическим напряжением в световоде и (или) эллиптическим сечением светонесущей жилы (кора), и во-вторых, обусловленное намоткой линейное двулучепреломление. Кроме того, может иметь место возникающее вследствие ряда причин циркулярное двулучепреломление ОВС. Особенно значительным циркулярным двулучепреломлением характеризуются так называемые spun-световоды [10-23]. Такие световоды при вытяжке из преформы (заготовки) испытывают сильное механическое закручивание, которое при остывании „вмораживается“ в структуру световода. В то же время spun-световоды имеют сильное невозмущенное линейное двулучепреломление и линейное двулучепреломление, обусловленное намоткой на катушку. Отметим также, что, как показано в [24], при весьма сильных кручениях (порядка $2 \mathrm{rev} / \mathrm{mm}$ ) в spunсветоводах (несмотря на то что их закручивание происходит в зоне плавления световода) уменьшается диаметр оптической моды, возрастают оптические потери, уменьшается длина волны отсечки $\lambda_{\text {cutoff }}$ (при $\lambda>\lambda_{\text {cutoff }}$ потери света в ОВС резко возрастают), и подавляется поляризационная модовая дисперсия [25,26], приводящая к уширению коротких оптических импульсов в связных световодах. Как будет показано ниже, вычисление СПИ на выходе spun-световода является довольно сложной задачей.

В работах [10-23] были проведены экспериментальные исследования spun-световодов, а также получены весьма приближенные аналитические решения для эволюции СПИ при его распространении в этих световодах. В частности авторы [10-23] пришли к выводу, что в spun-световодах имеет место подавление их невозмущенного линейного двулучепреломления, обусловленного наличием напрягающих вставок в световоде, эллиптической формой напрягающей отражающей оболочки или эллиптической формой кора [7]. Как показано в [15], данное явление позволяет эффективно применять spunсветоводы для изготовления датчиков электрического тока и магнитного поля, оптических изоляторов на эффекте Фарадея $[13,14]$. Отметим, что в самое последнее время появились скрученные ОВС с кором на основе фотонного кристалла, предназначенные для создания датчиков тока [27]. Однако количественные характеристики подавления невозмущенного линейного двулучепреломления в spun-световодах в [10-23] не были приведены.

На отсутствие полного понимания процесса эволюции СПИ в spun-световодах указывает, например, полемическое название работы [20]: „Оптические волокна spun: спиральная структура линейного двулучепреломления или циркулярное двулучепреломление“. При этом авторы [20] делают вывод о существовании именно спиральной структуры линейного двулучепреломления, которая и подавляет как невозмущенное линейное двулучепреломление, так и линейное двулучепреломление, обусловленное намоткой световода на катушку. Напротив, авторы $[15,28]$ придерживаются противоположной точки зрения.

Целью настоящей работы является получение количественных зависимостей параметров поляризационных мод, эллиптичности и азимута большой оси эллипса, а также интегрального эллиптического двулучепреломления от длины намотанного на катушку кварцевого spunсветовода для различных диаметров катушки и шага кручения световода. Вычисления проводились методом численного моделирования матриц Джонса [29], использованным авторами ранее в работе [7] (см. также $[8,9]$ ). Для отображения эволюции СПИ при его распространении в spun-световодах использовался метод сферы Пуанкаре СП) [9,29-33].

Случайные кручения осей ОВС, возникающие при его вытяжке из преформы вследствие крутильных колебаний еще не вполне застывшего волокна, здесь не рассматривались, поскольку, как показано в [34] (см. также [8,9]), сильное регулярное кручение подавляет влияние слабых случайных кручений в ОВС. Для вычислений на достаточно коротком отрезке spun-световода использовался формализм винтовых поляризационных мод В.Л. Гинзбурга (ВПМГ) [9,32,33,35].

В данной работе рассмотрен наиболее простой, нерезонансный случай, когда значения линейного двулуче- 
преломления, невозмущенного, обусловленного намоткой световода на катушку и обусловленного кручением spun-световода не совпадают между собой.

\section{2. Различные типы двулучепреломления одномодовых волоконных spun-световодов. Обзор литературы}

Двулучепреломление ОВС произвольного типа может быть линейным, циркулярным или эллиптическим, а его величина характеризуется параметром $\beta=\frac{2 \pi \Delta n}{\lambda}$, где $\Delta n-$ разность показателей преломления в медленной и быстрой осях ОВС, $\lambda$ - длина волны света. Размерность величины $\beta-\mathrm{rad} / \mathrm{m}$, и соответственно разность фаз излучения, прошедшего по медленной и быстрой осям $\mathrm{OBC}$, составляет $\delta=\beta z$, где $z$ - длина ОВС. В подавляющем большинстве случаев основным элементом оптоволоконных датчиков различных физических параметров является OBC, намотанный на катушку. В этом случае кроме невозмущенного линейного двулучепреломления $\beta_{0}$ имеет место также линейное двулучепреломление $\beta_{\text {coil }}$, обусловленное изгибным напряжением вследствие намотки на катушку. Невозмущенное линейное двулучепреломление spun-световодов в принципе может быть как сильным, так и слабым [7,9]. В данной работе мы рассматриваем spun-световоды с сильным невозмущенным линейным двулучепреломлением. Каждое из типов двулучепреломления, $\beta_{0}$ и $\beta_{\text {coil }}$, имеет свою пространственную ориентацию медленной и быстрой осей линейного двулучепреломления. В этих осях тензор диэлектрической проницаемости spun-световода диагонален в отсутствие одного из факторов $-\beta_{0}$ или $\beta_{\text {coil. }}$ При этом если направление осей $\beta_{\text {coil }}$ всегда фиксировано относительно волоконной катушки, то направление осей $\beta_{0}$ меняется вдоль длины ОВС вследствие кручения spun-световода.

Поскольку величины $\beta_{0}$ и $\beta_{\text {coil }}$ являются скалярными, то для избежания неоднозначности в обозначениях введем векторы $\mathfrak{B}_{0}$ и $\mathfrak{B}_{\text {coil }}$ так, что $\left|\mathfrak{B}_{0}\right|=\beta_{0},\left|\mathfrak{B}_{\text {coil }}\right|=\beta_{\text {coill }}$. Как показано на рис. 1 , оба этих вектора лежат в плоскости $X Y$, которая ортогональна оси OBC $Z$. Можно для удобства ввести еще две системы координат, $X^{\prime} Y^{\prime}$ и $X^{\prime \prime} Y^{\prime \prime}$, которые также лежат в плоскости $X Y$ и повернуты относительно системы координат $X Y$ соответственно на углы $\eta$ и $\varphi$.

Если для определенности принять, что пространственная ориентация вектора $\mathfrak{B}_{\text {coil }}$ совпадает с медленной осью линейного двулучепреломления ОВС, то удобно положить направление вектора $\mathfrak{B}_{\text {coil }}$ вдоль оси $X$ (рис. 1). При этом вектор $\mathfrak{B}_{\text {coil }}$ сохраняет свою ориентацию вдоль длины spun-световода. Азимут вектора $\mathfrak{B}_{0}$ в скрученном световоде равномерно вращается вдоль длины spun-световода. Направление вектора $\mathfrak{B}_{0}$ совпадает с осью $X^{\prime}$ (рис. 1), которая также вращается. Как показано в $[1,2]$ (см. также [36]), в системе координат $X^{\prime} Y^{\prime}$

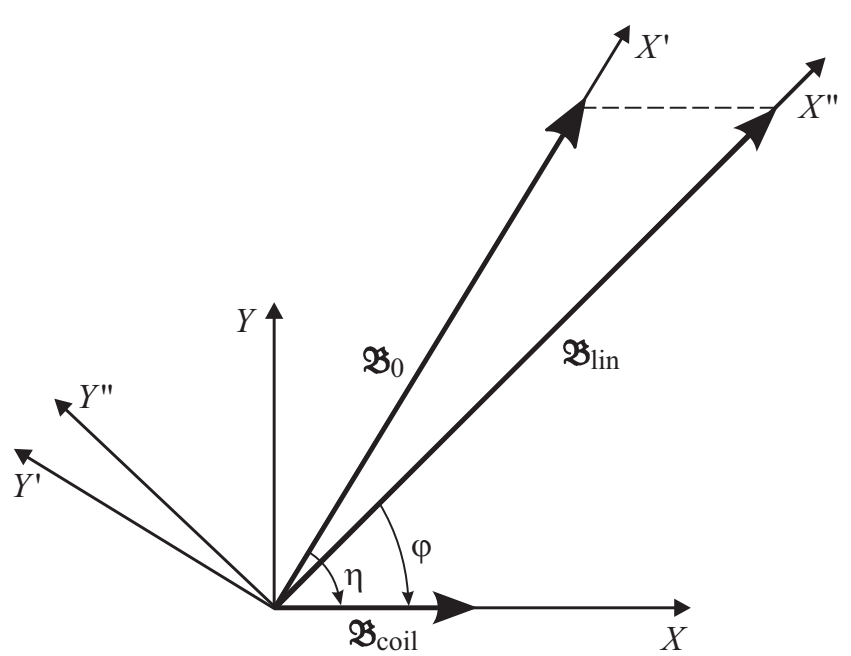

Рис. 1. Формирование линейного двулучепреломления в spunволокнах в результате векторного сложения невозмущенного линейного двулучепреломления и линейного двулучепреломления, обусловленного намоткой на катушку.

тензор диэлектрической проницаемости ОВС, связанный исключительно с невозмущенным линейным двулучепреломлением, принимает диагональный вид. Именно в этой вращающаяся системе координат $X^{\prime} Y^{\prime}$ и существуют ВПМГ [35].

Вопрос о суммировании векторов $\mathfrak{B}_{\text {coil }}$ и $\mathfrak{B}_{0}$, т.е. об интегральном линейном двулучепреломлении намотанных на катушку spun-световодов, рассмотрим в разд. 4. Здесь же уточним ряд моментов относительно различных типов двулучепреломления в spun-световодах.

Вопрос о величине и направлении $\mathfrak{B}_{\text {coil }}$ начал рассматриваться еще сорок лет назад [37-41]. В работе [40] было показано, что для кварцевого ОВС быстрая ось линейного двулучепреломления лежит в плоскости волоконного витка, а медленная ось и соответственно вектор $\mathfrak{B}_{\text {coil }}$ перпендикулярны плоскости этого витка. Если образующая катушки с намотанным световодом ориентирована вдоль оси $X$, и соответственно витки OBC лежат в плоскости $Y Z$, то направление вектора $\mathfrak{B}_{\text {coil }}$ (медленная ось) совпадает с осью $X$ (рис. 1) [42]. Соответственно быстрая ось связанного с намоткой ОВС линейного двулучепреломления направлена вдоль оси $Y[42]$. Как показано в $[40,42]$

$$
\Delta n_{\text {coil }}=n_{X}-n_{Y}=n_{\text {slow }}-n_{\text {fast }}=1.33\left(\frac{D_{f}}{D_{\text {coil }}}\right)^{2},
$$

где $D_{f}-$ внешний диаметр ОВС (без учета толщины защитного жакета), $D_{\text {coil }}$ - диаметр намотки $\mathrm{OBC}, n_{X}$ и $n_{Y}$ - показатели преломления вдоль осей двулучепреломления ОВС $X$ и $Y, n_{\text {slow }}$ и $n_{\text {fast }}-$ показатели преломления в медленной и быстрой осях двулучепреломления ОВС. В рассматриваемом случае $n_{X}=n_{\text {slow }}$, a $n_{Y}=n_{\text {fast }}{ }^{1}$ Выражение (1) удобно тем, что

\footnotetext{
${ }^{1}$ Более подробно этот вопрос рассмотрен в монографии [42].
} 
оно справедливо для произвольной длины волны света. Величина линейного двулучепреломления $\beta_{\text {coil }}$ связана с величиной $\Delta n_{\text {coil }}$ таким же соотношением как и $\beta_{0} \mathrm{c} \Delta n_{0}$ : $\beta_{0, \text { coil }}=2 \pi \Delta n_{0, \text { coil }} / \lambda$, где $\lambda$ - длина волны света.

Отметим, что обусловленное намоткой линейное двулучепреломление ОВС $\beta_{\text {coil }}$ позволило разработать весьма удобные поляризационные контроллеры $[40,42,43]$, с помощью которых можно создавать произвольное СПИ в ОВС. В англоязычной литературе эти контроллеры иногда именуются по имени их изобретателя [40] „Петлей Лефевра“, а в СССР и России - „поляризационными управителями Лефевра“. Существуют и другие поляризационные контроллеры, в которых, например, используется поперечное давление на ОВС под различными углами с помощью трех электромагнитных реле [44], или основанные на применении эффекта Фарадея[45]. Однако практическое применение нашли только поляризационные контроллеры $[40,42,43]$, поскольку они не требуют электропитания, и следовательно, не нагревают световод.

Следует иметь в виду, что в намотанном на катушку ОВС всегда возникает некоторое циркулярное двулучепреломление той или иной природы. Если производить намотку световода так, чтобы ориентации осей его невозмущенного линейного двулучепреломления $\beta_{0}$ на предыдущем и последующем витках совпадали, ${ }^{2}$ то, как показано в [31,53], возникает механическое торсионное кручение ОВС. Погонное кручение волокна $\Theta$ (размерность $\mathrm{rad} / \mathrm{m}$ ) и угол поворота осей линейного двулучепреломления на одном витке волокна $\vartheta$ определяются следующими выражениями [31,53,54]:

$$
\begin{aligned}
& \Theta=\frac{2 \pi H}{\left(\pi D_{\text {coil }}\right)^{2}+H^{2}}, \\
& \vartheta=\frac{2 \pi H}{\sqrt{\left(\pi D_{\text {coil }}\right)^{2}+H^{2}}},
\end{aligned}
$$

где $H$ - шаг намотки ОВС. Если световод укладывается на катушку без зазоров, „виток к витку“, а толщина защитного покрытия (жакета) ОВС мала по сравнению с $D_{f}$, то $H \sim D_{f} \ll D_{\text {coil }}$, и, как следует из выражения (2), наведенное циркулярное двулучепреломление будет сравнительно невелико.

Если наматывать световод на катушку так, чтобы в нем не возникали торсионные напряжения, то ориентации осей его невозмущенного линейного двулучепреломления $\beta_{0}$ на предыдущем и последующем витках будут отличаться, и возникнет циркулярное двулучепреломление, обусловленное эффектом Рытова $[55,56]$. В этом случае угол поворота плоскости поляризации света на одном витке ОВС на цилиндрической катушке составляет $[31,53,54]$ :

$$
\alpha_{\mathrm{Ryt}}=2 \pi\left(1-\frac{H}{\sqrt{\left(\pi D_{\mathrm{coil}}\right)^{2}+H^{2}}}\right) .
$$

2 Это условие выполняется автоматически при укладке так называемого ленточного ОВС $[8,9,46-52]$.
Может показаться, что угол $\alpha_{\text {Ryt }}$ достаточно велик. Однако если бы эффект Рытова отсутствовал (например, намотка ОВС состояла бы всего из одного витка, причем он был бы намотан „встык“, то есть без сдвига световода от начала витка к его концу $(H=0))$, то в скобках в выражении (3) стояла бы единица. Этому соответствует просто поворот азимута линейной поляризации излучения на угол $2 \pi$ при прохождении излучением одного витка световода. Таким образом, в реальных катушках с ОВС циркулярное двулучепреломление, обусловленное эффектом Рытова, весьма невелико. Для возможности регистрации эффекта Рытова в ОВС осуществляют его специальную намотку с большим шагом $H$ так, чтобы витки отстояли далеко друг от друга [54].

Однако существуют задачи, когда необходимо создать сильное торсионное кручение ОВС. В частности, это нужно для создания датчиков тока и магнитного поля [15], оптических изоляторов на эффекте Фарадея $[13,14]$. В ОВС с линейным двулучепреломлением эффект Фарадея может накапливаться только на длине поляризационных биений $L_{b}=\lambda / \Delta n_{0}$, которая для ОВС с сильным линейным двулучепреломлением составляет всего 1-10 mm [7-9]. В ОВС со слабым линейным двулучепреломлением величина $L_{b}$ может составлять от метра до сотен метров, но такие световоды не сохраняют СПИ, которое меняется случайным образом при незначительном изменении температуры. Данная проблема решается с помощью торсионного кручения OBC (twist), приводящего к возникновению циркулярного двулучепреломления, которое в невращающейся системе координат записывается как

$$
\beta_{\mathrm{tw}}^{\mathrm{lab}}=g \Theta
$$

где $g$ - коэффициент фотоупругости оптического материала световода. Теоретическое значение $g$ для кварца при комнатной температуре составляет 0.08 [57], экспериментально измеренное $-0.065 \pm 0.005$ [4] и $0.073[10]$. При закручивании кварцевых ОВС в процессе их вытяжки в зоне плавления, что имеет место для spun-световодов, можно положить $g \simeq 0$, поскольку в зоне плавления кручение не вызывает торсионных напряжений. Отметим, что в некоторых работах (например $[4,41,42,57])$ для $\beta_{\mathrm{tw}}^{\mathrm{lab}}$ приводится его удвоенное значение по сравнению с (4): $\beta_{\mathrm{tw}}^{\mathrm{lab}}=2 g \Theta$. Это связано с различными обозначениями циркулярного двулучепреломления - в работах $[4,41,42,57]$ величина $g$ в два раза меньше, чем в выражении (4). Однако в случае, когда рассматривается угол поворота $\rho$ плоскости линейной поляризации света в оптической среде длиной $l$, кручением $\Theta$ и полным углом кручения $\xi=\Theta l$, то, как показано в [42], $\rho=0.07 \xi \simeq g \xi$ или $\rho \simeq g \Theta l$, т.е. $\beta_{\mathrm{tw}}^{\mathrm{lab}}=g \Theta$. Мы так подробно остановились на этом довольно простом вопросе, потому что в разд. 3 мы будем рассматривать физическую природу и количественные характеристики обусловленного кручением оптической среды циркулярного двулучепреломления как в сопро- 
вождающей кручение винтовой, так и в невращающейся системах координат.

Как показано в работе В.Л. Гинзбурга [35], являющейся основополагающей для поляризационной оптики оптических сред с линейным двулучепреломлением и механическим кручением, величина $\beta_{\mathrm{tw}}^{\mathrm{lab}}$ будет принимать ненулевые значения только при условии, что в оптической среде с кручением (каковой, в частности, является ОВС) будет иметь место некоторое исходное (невозмущенное) линейное двулучепреломление. Физический смыл этого результата [35] можно наглядно пояснить следующим образом. Предположим, что имеется изотропная оптическая среда, состоящая из очень тонких оптических пластинок толщиной много меньше длины волны света. Если вторую пластинку повернуть на некоторый малый угол относительно первой, третью на такой же угол относительно второй и так далее (так называемый веерный поворот), то, несмотря на наличие кручения оптической среды, никакого вращения плоскости линейной поляризации света не возникнет, и оптическая среда останется изотропной. Теперь предположим, что рассматриваемая среда и соответственно тонкие оптические пластинки имеют некоторое линейное двулучепреломление. Тогда рассмотренный выше веерный поворот пластинок вызовет вращение плоскости линейной поляризации света, т.е. возникнет циркулярное двулучепреломление. Это явление происходит потому, что при достаточно малых углах поворота каждой из пластинок азимут линейной поляризации света адиабатически отслеживает поворот осей линейного двулучепреломления. ${ }^{3}$ В этом и заключается решающая роль исходного линейного двулучепреломления в создании обусловленного кручением оптической среды циркулярного двулучепреломления. К этому вопросу мы вернемся в разд. 4, где с помощью матриц Джонса рассмотрим количественные характеристики циркулярного двулучепреломления, наведенного кручением оптической среды. Для всех типов двулучепреломления ОВС обычно используется размерность $\mathrm{rad} / \mathrm{m}$.

Следует отметить, что торсионное кручение холодного ОВС зачастую приводит к его разрыву. Для предотвращения такого разрыва применяют специальную методику скрутки ОВС при наличии его продольного подтягивания [59], что практически не осуществимо при одновременной его намотке на катушку. Но если провести закрутку ОВС еще в зоне плавления преформы (заготовки), из которой производится вытяжка световода, то, как было указано выше, торсионных напряжений не возникнет. Из соображений упрощения технологии вытяжки вращают не вытягиваемый световод, а преформу. Такая технология вытяжки ОВС была описана в работах английских авторов [10-12], где было предложено именовать такие ОВC spun-световодами. Ввиду того что

\footnotetext{
3 Это утверждение доказано в [35] (см. также [33]) методом геометрооптического приближения, а в [58] с помощью полиномов Чебышева.
}

в полужидком состоянии в ОВС не возникает механических напряжений, то соответственно не возникает и эффекта фотоупругости. Поэтому для spun-световодов можно положить $g \simeq 0$. Исследование spun-световодов проводилось в Англии в 80-е годы прошлого века [10-15] и в последнее время в России [16-23].

\section{3. Характеристики циркулярного двулучепреломления скрученных OBC в невращающейся и сопровождающей кручение системах координат}

Запишем выражение для матрицы Джонса обычного OBC (т. е. не spun-световода) длиной $z$ с коэффициентом фотоупругости $g$ и постоянными кручением $\Theta=d \rho / d z$ (где $\rho-$ угол поворота ОВС на некоторой длине $z$ ) и невозмущенным линейным двулучепреломлением $\beta_{0}$ в невращающейся системе координат ${ }^{4}$ [7-9]:

$$
M(z)=T(-\rho) M^{e},
$$

где $\rho=\Theta z, T(\rho)$ - матрица поворота на угол $\rho$ :

$$
T(\rho)=\left(\begin{array}{rr}
\cos \rho & \sin \rho \\
-\sin \rho & \cos \rho
\end{array}\right),
$$

$M^{e}$ - матрица Джонса ВПМГ в сопровождающей кручение системе координат

$$
M^{e}=\left(\begin{array}{cc}
\cos \frac{\delta}{2}+i \frac{\beta_{0}}{\beta^{e}} \sin \frac{\delta}{2} & \frac{2(1-g) \Theta}{\beta^{e}} \sin \frac{\delta}{2} \\
-\frac{2(1-g) \Theta}{\beta^{e}} \sin \frac{\delta}{2} & \cos \frac{\delta}{2}-i \frac{\beta_{0}}{\beta^{e}} \sin \frac{\delta}{2}
\end{array}\right),
$$

$\beta^{e}=\sqrt{\beta_{0}^{2}+(2(1-g) \Theta)^{2}}$ - эллиптическое двулучепреломление скрученного ОВС в сопровождающей кручение винтовой системе координат, $\delta=\beta^{e} z-$ разность фаз излучения, прошедшего по медленной и быстрой осям эллиптического двулучепреломления скрученного ОВС.

Рассмотрим здесь одну важную особенность представления циркулярного двулучепреломления в формализме матриц Джонса ВПМГ. В недиагональных элементах матрицы (7) имеется множитель, представляющий собой отношение удвоенного кручения осей двулучепреломления ОВС, $2(1-g) \Theta$, к эллиптическому двулучепреломлению $\beta^{e}$. Таким образом, величина $2(1-g) \Theta$ есть циркулярное двулучепреломление, фигурирующее в матрице Джонса ВПМГ. Поскольку величина $2(1-g) \Theta$ рассчитывается в сопровождающей кручение винтовой

\footnotetext{
${ }^{4}$ Для простоты здесь не будем рассматривать линейное двулучепреломление, связанное с намоткой ОВС на катушку. Отметим, что в этом случае интегральная и локальная матрицы Джонса совпадают.
} 
(геликоидальной) системе координат, то для удобства введем обозначение:

$$
\beta_{\mathrm{tw}}^{\text {helic }}=2(1-g) \Theta .
$$

Сравнивая выражения (4) и (8) можно видеть, что они дают разные определения циркулярного двулучепреломления. При $g=0.06-0.08$ различие величин $\beta_{\mathrm{tw}}^{\mathrm{lab}}$ из (4) и $\beta_{\mathrm{tw}}^{\text {helic }}$ из (8) составляет 24-32 раза. Ниже мы покажем, что такое большое различие связано с тем, что выражение (4) представляет циркулярное двулучепреломление в невращающейся системе координат, а выражение (8) - в сопровождающей кручение оптической среды (в данном случае ОВС) винтовой системе координат.

Для упрощения расчетов предположим здесь, что исходное линейное двулучепреломление в ОВС отсутствует, т.е. в матрице Джонса (7) $\beta_{0}=0$. Выше было отмечено, что, как показано в работе [35], величина $\beta_{\mathrm{tw}}^{\mathrm{lab}}$ будет принимать ненулевые значения только при условии, что $\beta_{0} \neq 0$. Однако, как будет показано ниже, при $g \neq 0$ даже если $\beta_{0}=0, \beta_{\mathrm{tw}}^{\mathrm{lab}} \neq 0$. При $\beta_{0}=0$ эллиптическое двулучепреломление $\beta_{e}=2(1-g) \Theta$, и матрица Джонса (7) примет вид

$$
M_{0}^{e}=\left(\begin{array}{rr}
\cos \delta / 2 & \sin \delta / 2 \\
-\sin \delta / 2 & \cos \delta / 2
\end{array}\right)=T(\delta / 2)
$$

где $\delta=2(1-g) \Theta z$. Поскольку $T((1-g) \Theta z)=T((1-g) \rho)$, то согласно (5) $M(z)=T(-\rho) T((1-g) \rho)=T(g \rho)=$ $=T(g \Theta z)$. Отсюда следует, что циркулярное двулучепреломление в невращающейся системе координат составляет $\beta_{\mathrm{tw}}^{\text {lab }}=g \Theta$, что совпадает с выражением (4).

Итак, мы показали, что для скрученных оптических сред циркулярное двулучепреломление в невращающейся и сопровождающей кручение системах координат есть две различные величины. Это не вызывало сомнений, так как речь идет о разных волнах. Кроме того, мы показали, что величина $\beta_{\mathrm{tw}}^{\mathrm{lab}}$ будет принимать ненулевые значения не только при условии $\beta_{0} \neq 0$, но и при $g \neq 0$. Отметим, что на примере веерного последовательного расположения тонких изотропных оптических пластинок, рассмотренном в разд. 2, механических торсионных напряжений не возникает, поскольку при повороте пластинки свободно скользят вдоль друг друга. В этом случае и $\beta_{0}=0$, и $g=0$, и, как показано в разд. 2, $\beta_{\mathrm{tw}}^{\mathrm{lab}}=0$.

\section{4. Расчет локальных параметров двулучепреломления одномодовых spun-световодов при наличии намотки и кручения}

Рассмотрим особенности эволюции линейного двулучепреломления в намотанных на катушку spun-световодах, используя теорию возмущений по показателям преломления вдоль медленной и быстрой осей. Условие применимости теории возмущений можно записать в виде $\Delta n \ll n$, где $n=\left(n_{X}+n_{Y}\right) / 2-$ среднее значение показателей преломления ОВС $n_{X}, n_{Y}$ в медленной и быстрой осях, $n_{X}=n+\Delta n / 2, n_{Y}=n-\Delta n / 2$.

Вернемся к рис. 1 , где представлено сложение векторов невозмущенного линейного двулучепреломления $\mathfrak{B}_{0}$ и обусловленного намоткой ОВС линейного двулучепреломления $\mathfrak{B}_{\text {coil }}$. Выше, в разд. 2 , мы ввели угол $\eta$ между векторами $\mathfrak{B}_{0}$ и $\mathfrak{B}_{\text {coil }}$, т. е. между осями $X$ и $X^{\prime}$. Этот угол меняется с длиной ОВС $z$ по линейному закону, поскольку кручение spun-световодов является равномерным. Отметим, что для ОВС с сильным невозмущенным линейным двулучепреломлением, как правило, выполняется условие $\beta_{0} \gg \beta_{\text {coil }}$. То есть в невращающейся системе координат $X Y$ вектор $\mathfrak{B}_{\text {coil }}$ мал и неподвижен, а вектор $\mathfrak{B}_{0}$ - велик и вращается с пространственным периодом кручения ОВС $L_{\text {coil }}=2 \pi / \beta_{\text {coil }}$.

Запишем выражения для зависимостей от длины spunсветовода $z$ суммарного локального линейного двулучепреломления $\beta_{\text {lin }}=\left|\mathfrak{B}_{\text {lin }}\right|\left(\mathfrak{B}_{\text {lin }}=\mathfrak{B}_{0}+\mathfrak{B}_{\text {coil }}\right)$, угла $\varphi$ между осью $X$ и вектором $\mathfrak{B}_{\text {lin }}$ (рис. 1 ), а также локального кручения осей линейного двулучепреломления $\Theta$ :

$$
\begin{array}{r}
\beta_{\text {lin }}(z)=\sqrt{\beta_{0}^{2}+\beta_{\text {coil }}^{2}+2 \beta_{0} \beta_{\text {coil }} \cos \eta(z)}, \\
\varphi(z)=\arctan \frac{\beta_{0} \sin \eta(z)}{\beta_{0} \cos \eta(z)+\beta_{\text {coil }}}, \\
\Theta(z)=\frac{d \varphi}{d z}=\frac{\beta_{\mathrm{tw}} \beta_{0}\left(\beta_{0}+\beta_{\text {coil }} \cos \eta(z)\right)}{\beta_{0}^{2}+\beta_{\text {coil }}^{2}+2 \beta_{0} \beta_{\text {coil }} \cos \eta(z)},
\end{array}
$$

где $\eta(z)=\beta_{\mathrm{tw}} z, \beta_{\mathrm{tw}}=2 \pi / L_{\mathrm{tw}}$, a $L_{\mathrm{tw}}$ - длина, на которой spun-световод закручивается на $360^{\circ}$.

Здесь следует особо подчеркнуть, что вектор $\mathfrak{B}_{\text {lin }}$ совпадает с осью $X^{\prime \prime}$ системы координат $X^{\prime \prime} Y^{\prime \prime}$. В системе координат $X^{\prime \prime} Y^{\prime \prime}$ тензор диэлектрической проницаемости для суммарного линейного двулучепреломления намотанного на катушку spun-световода принимает диагональный вид [1,2].

Отметим, что вопрос о том, в каком пространстве осуществляется суммирование векторов $\mathfrak{B}_{\text {coil }}$ и $\mathfrak{B}_{0}$, ранее приводил к ряду недоразумений. Например, в работах $[4,60]$ векторы $\mathfrak{B}_{\text {coil }}$ и $\mathfrak{B}_{0}$ (в $[4,60]$ они имели другое обозначение) рассматривались в пространстве векторов Стокса и исходили из центра СП. Между тем модули векторов Стокса есть величины безразмерные, а модули векторов $\mathfrak{B}_{\text {coil }}$ и $\mathfrak{B}_{0}$ имеют размерность $\mathrm{rad} / \mathrm{m}$. В диссертации [61] сложение рассматриваемых векторов проводилось на некоторой комплексной плоскости, оси на которой даже не были обозначены. Здесь мы использовали суммирование векторов $\mathfrak{B}_{\text {coil }}$ и $\mathfrak{B}_{0}$ в реальном пространстве, в плоскости, ортогональной оптической оси ОВС. Однако усредненные поляризационные моды протяженного отрезка намотанного на катушку spunсветовода в невращающейся системе координат не могут быть описаны непосредственно с помощью формализма 
матрицы Джонса ВПМГ, поскольку, как показано на рис. 1, вектор $\mathfrak{B}_{\text {lin }}$ вращается неравномерно.

В принципе с учетом обусловленного кручением spun-световода циркулярного двулучепреломления можно было бы получить выражение для матрицы Джонса протяженного отрезка такого ОВС. Практически, однако, это не представляется возможным, поскольку требует решения дифференциального уравнения Риккати в общем виде. Решение этого уравнения можно получить для равномерного кручения осей линейного двулучепреломления ОВС, однако в общем случае оно не имеет решения в квадратурах (см., например, [62]). Кроме того, как показано в [1,2], точные решения существуют и для экспоненциального (нарастающего и затухающего) закона кручения осей линейного двулучепреломления ОВС. Однако в рассматриваем случае угол $\varphi$ меняется по довольно сложному закону (11), и в лучшем случае можно получить только приближенное решение дифференциального уравнения Риккати. Эта задача является предметом отдельного исследования и будет рассмотрена нами в ближайшее время. Поэтому в отличие от системы координат $X^{\prime} Y^{\prime}$, которая равномерно вращается относительно невращающейся системы координат $X Y$, строго вычислить закон вращения системы координат $X^{\prime \prime} Y^{\prime \prime}$ невозможно. Можно только определить угол $\varphi$ на локальном отрезке намотанного на катушку spun-световода.

Отметим также, что уравнение Риккати, описывающее линейную трансформацию поляризационных мод в намотанных на катушку spun-световодах, является нелинейным дифференциальным уравнением, поскольку в его правой части содержится квадратичный член. Эта нелинейность не имеет отношения к зависимости интенсивности излучения от длины ОВС и проявляется в виде поляризационных явлений, в частности, как нелинейная зависимость отношения ортогональных компонент вектора электрического поля световой волны $E_{y} / E_{x}$ от длины ОВС. Как будет показано ниже, нелинейность приводит к возникновению небольших квазигармонических осцилляций параметров двулучепреломления spunсветоводов в зависимости от длины волокна. Это явление имеет аналог - возникновение под действием поперечного по отношению к направлению светового луча магнитного поля эффекта Коттона-Мутона, который также приводит к осцилляциям отношения $E_{y} / E_{x}$ в зависимости от длины оптической среды. Отметим, что циркулярное двулучепреломление, связанное с кручением spun-световода, также имеет аналог - эффект Фарадея, но в отличие от описанного выше явления кручение не приводит к невзаимному циркулярному двулучепреломлению.

Вследствие вышесказанного для получения матрицы Джонса протяженного отрезка spun-световода мы применили метод численного моделирования, предложенный нами двадцать лет назад [7] (этот метод также рассмотрен в наших монографиях $[8,9])$. Напомним, что в [7-9] рассматривались случайные кручения осей линейного двулучепреломления обычного ОВС (не spunсветовода), возникающие в процессе его вытяжки из преформы вследствие крутильных колебаний еще не застывшего волокна. Как показано в [7-9], эти случайные кручения характеризуются тем, что на длине OBC порядка $2-3 \mathrm{~cm}$ кручение остается практически постоянным, а потом меняется скачком. Соответственно в ходе численного моделирования в [7-9] вычислялись матрицы Джонса для каждого такого отрезка ОBC, a матрица Джонса всего световода получалась как последовательное произведение матриц отрезков. Такой же прием можно применить для вычисления матрицы Джонса spun-световода.

В рассматриваемой здесь задаче численное моделирование осложняется тем, что величина $\beta_{\operatorname{lin}}(z)$ (10), a также величина кручения осей линейного двулучепреломления spun-световода $\Theta(z)$ (12) меняются непрерывно вдоль световода. Вследствие этого для обеспечения необходимой точности вычислений длина spun-световода разбивалась на достаточно короткие (порядка десятков $\mu \mathrm{m}$ ) участки одинаковой длины $l \ll L_{b}, L_{\mathrm{tw}}, L_{\text {coil }}$, непрерывные параметры на $k$-м участке считались постоянными и заменялись их значением при $z=k l$. Для каждого такого отрезка световода вычислялась матрица Джонса, и в результате последовательного перемножения всех этих матриц получалась матрица Джонса всего spun-световода.

\section{5. Расчет эволюции интегральных параметров поляризационных мод, состояния поляризации и интегрального двулучепреломления намотанных на катушку одномодовых spun-световодов}

Матрица Джонса ВПМГ для $k$-го короткого отрезка spun-световода $(g=0)$ длиной $l$ в винтовой (т. е. сопровождающей кручение ОВС) системе координат имеет вид [7-9]:

$$
M_{k}^{e}=\left(\begin{array}{cc}
\cos \frac{\delta_{k}}{2}+i \frac{\beta_{k}}{\beta_{k}^{e}} \sin \frac{\delta_{k}}{2} & \frac{2 \Theta_{k}}{\beta_{k}^{e}} \sin \frac{\delta_{k}}{2} \\
-\frac{2 \Theta_{k}}{\beta_{k}^{e}} \sin \frac{\delta_{k}}{2} & \cos \frac{\delta_{k}}{2}-i \frac{\beta_{k}}{\beta_{k}^{e}} \sin \frac{\delta_{k}}{2}
\end{array}\right) .
$$

Здесь $\beta_{k}=\beta_{\text {lin }}\left(l_{k}\right)$ - среднее значение линейного двулучепреломления (10) на $k$-м отрезке spun-световода, $\Theta_{k}=\Theta\left(l_{k}\right)$ - средняя скорость кручения осей ОВС (12) на $k$-м отрезке spun-световода, $\beta_{k}^{e}=\sqrt{\beta_{k}^{2}+4 \Theta_{k}^{2}}-$ среднее значение эллиптического двулучепреломления на $k$-м отрезке spun-световода, $\delta_{k}=\beta_{k}^{e} l-$ разность фаз излучения, прошедшего по медленной и быстрой осям ВПМГ, на $k$-м отрезке ОВС. Компоненты вектора электрического поля на выходе протяженного отрезка spun- 
световода определяются [7-9] соотношением

$$
\begin{aligned}
\left(\begin{array}{c}
E_{x} \\
E_{y}
\end{array}\right) & =\prod_{k=1}^{N} M_{k}\left(\begin{array}{l}
A_{x}^{0} \\
A_{y}^{0} e^{i \psi_{o}}
\end{array}\right) \\
& =\prod_{k=1}^{N} T\left(-\varphi_{k}\right) M_{k}^{e} T\left(\varphi_{k-1}\right)\left(\begin{array}{l}
A_{x}^{0} \\
A_{y}^{0} e^{i \psi_{o}}
\end{array}\right)= \\
& =T\left(-\sum_{k=1}^{N} \Theta_{k} l\right) \prod_{k=1}^{N} M_{k}^{e}\left(\begin{array}{l}
A_{x}^{0} \\
A_{y}^{0} e^{i \psi_{o}}
\end{array}\right),
\end{aligned}
$$

где $N$ - число участков длины $l$ в волокне, $\varphi_{k}-$ ориентация медленной оси двулучепреломления на выходе $k$-го отрезка волокна (или на входе $(k+1)$-го отрезка), полагаем $\varphi_{0}=0, \varphi_{k}-\varphi_{k-1}=\Theta_{k} l,\left(\begin{array}{c}A_{x}^{0} \\ A_{y}^{0} e^{i \psi_{o}}\end{array}\right)-$ нормированный вектор Джонса излучения на входе ОВС $\left(\left(A_{x}^{0}\right)^{2}+\left(A_{y}^{0}\right)^{2}=1\right)$.

Из (14) можно получить выражения для зависимости нормированного вектора Стокса от длины световода на выходе ОВС $[7,8,29]$ :

$$
\left(\begin{array}{l}
S_{0} \\
S_{1} \\
S_{2} \\
S_{3}
\end{array}\right)=\left(\begin{array}{c}
A_{x}^{2}+A_{y}^{2} \\
A_{x}^{2}-A_{y}^{2} \\
2 A_{x} A_{y} \cos \psi \\
2 A_{x} A_{y} \sin \psi
\end{array}\right)
$$

где $A_{x}, A_{y}$ - амплитуды компонент $E_{x}, E_{y}, \psi-$ разность фаз между компонентами $E_{x}, E_{y}$ нормированного вектора Джонса на выходе ОВС $\left(A_{x}^{2}+A_{y}^{2}=S_{0}=1\right)$. Соответственно, используя (15), можно построить эволюцию СПИ на СП.

Для вычисления эффективных интегральных параметров всего spun-световода требуется записать суммарную матрицу Джонса. Отметим здесь очевидный факт произведение матриц Джонса ВПМГ отрезков ОВС с постоянными, но различными для каждой из матриц параметрами уже не есть матрица Джонса ВПМГ. Вследствие этого для записи интегральной матрицы будем использовать матрицу Джонса эллиптической фазовой пластинки в невращающейся системе координат [7-9,63]:

$$
M_{\Sigma}=T\left(-\alpha_{\Sigma}\right) M_{\Sigma}^{\prime} T\left(\alpha_{\Sigma}\right)
$$

где

$$
\begin{aligned}
& M_{\Sigma}^{\prime}= \\
& =\left(\begin{array}{cc}
\cos \frac{\beta_{\Sigma}^{e} z}{2}+i \cos 2 \chi_{\Sigma} \sin \frac{\beta_{\Sigma}^{e} z}{2} & \sin 2 \chi_{\Sigma} \sin \frac{\beta_{\Sigma}^{e} z}{2} \\
-\sin 2 \chi_{\Sigma} \sin \frac{\beta_{\Sigma}^{e} z}{2} & \cos \frac{\beta_{\Sigma}^{e} z}{2}-i \cos 2 \chi_{\Sigma} \sin \frac{\beta_{\Sigma}^{e} z}{2}
\end{array}\right) .
\end{aligned}
$$

Здесь $\alpha_{\Sigma}-$ азимут большой оси эллипса поляризации, $\chi_{\Sigma}$ - эллиптичность, $\beta_{\Sigma}^{e}$ - эллиптическое двулучепреломление отрезка волокна длины $z$. Теперь, представив матрицу, полученную в результате произведения матриц
Параметры spun-световодов [20]

\begin{tabular}{c|c|c|c|c|c|c|c}
\hline № & $\begin{array}{c}R_{\text {coil, }}, \\
\mathrm{mm}\end{array}$ & $\begin{array}{c}L_{\mathrm{tw}}, \\
\mathrm{mm}\end{array}$ & $\begin{array}{c}L_{\text {coil }}, \\
\mathrm{m}\end{array}$ & $\begin{array}{c}\beta_{\mathrm{tw}}, \\
\mathrm{rad} / \mathrm{m}\end{array}$ & $\begin{array}{c}\beta_{\text {coil }}, \\
\mathrm{rad} / \mathrm{m}\end{array}$ & $\Delta n_{\mathrm{tw}}$ & $\Delta n_{\text {coil }}$ \\
\hline 1 & 36 & 7.5 & 3.8275 & 837.76 & 1.6416 & $2.07 \cdot 10^{-4}$ & $4.05 \cdot 10^{-7}$ \\
2 & 20 & 7.5 & 1.1813 & 837.76 & 5.3188 & $2.07 \cdot 10^{-4}$ & $1.31 \cdot 10^{-6}$ \\
3 & 15 & 7.5 & 0.6645 & 837.76 & 9.4556 & $2.07 \cdot 10^{-4}$ & $2.33 \cdot 10^{-6}$ \\
4 & 10 & 7.5 & 0.2953 & 837.76 & 21.275 & $2.07 \cdot 10^{-4}$ & $5.25 \cdot 10^{-6}$ \\
5 & 36 & 2.5 & 3.8275 & 2513.3 & 1.6416 & $6.20 \cdot 10^{-4}$ & $4.05 \cdot 10^{-7}$ \\
6 & 20 & 2.5 & 1.1813 & 2513.3 & 5.3188 & $6.20 \cdot 10^{-4}$ & $1.31 \cdot 10^{-6}$ \\
7 & 15 & 2.5 & 0.6645 & 2513.3 & 9.4556 & $6.20 \cdot 10^{-4}$ & $2.33 \cdot 10^{-6}$ \\
8 & 10 & 2.5 & 0.2953 & 2513.3 & 21.275 & $6.20 \cdot 10^{-4}$ & $5.25 \cdot 10^{-6}$
\end{tabular}

коротких отрезков, в виде ${ }^{5}$

$$
M_{\Sigma}=\prod_{k=1}^{N} M_{k}=\left(\begin{array}{cc}
a & b \\
-b^{*} & a^{*}
\end{array}\right),
$$

можно вычислить интегральные параметры:

$$
\begin{aligned}
& \beta_{\Sigma}^{e}=\frac{2 \arccos (\operatorname{Re} a)}{z}, \\
& \alpha_{\Sigma}=\frac{1}{2} \arctan \left(\frac{\operatorname{Im} b}{\operatorname{Im} a}\right), \\
& \chi_{\Sigma}=\frac{1}{2} \arcsin \left(\frac{\operatorname{Re} b}{\sqrt{1-(\operatorname{Re} a)^{2}}}\right) .
\end{aligned}
$$

Подчеркнем, что выражение (16) записано в невращающейся системе координат, а выражение (17) - во вращающейся системе координат. Что касается выражений (18), то параметры $\beta_{\Sigma}^{e}$ и $\chi_{\Sigma}$ рассматриваются во вращающейся системе координат, а параметр $\alpha_{\Sigma}$, естественно, в невращающейся системе координат, поскольку в сопровождающей кручение системе координат вращение осей интегрального эллиптического двулучепреломления не имеет места.

\section{6. Результаты численного моделирования}

Для проведения численного моделирования мы использовали параметры spun-световодов, которые были экспериментально исследованы в работе [20]: невозмущенная длина поляризационных биений $L_{b}=15 \mathrm{~mm}$, внешний диаметр световода $D_{f}=125 \mu \mathrm{m}$, невозмущенное линейное двулучепреломление $\beta_{0}=418.88 \mathrm{rad} / \mathrm{m}$ $\left(\Delta n_{0}=1.03 \cdot 10^{-4}\right)$, длина волны света $\lambda=1.55 \mu \mathrm{m}$. В [20] рассматривались spun-световоды с двумя различными пространственными периодами кручения $L_{\mathrm{tw}}$ и четырьмя различными радиусами катушки $R_{\text {coil }}=D_{\text {coil }} / 2$. Эти параметры приводятся в таблице (где $\left.\beta_{0, \mathrm{coil}, \mathrm{tw}}=2 \pi \Delta n_{0, \mathrm{coil}, \mathrm{tw}} / \lambda\right)$.

\footnotetext{
5 Здесь * означает комплексное сопряжение.
} 
Результаты численного моделирования зависимостей от длины световода $z$ эффективного интегрального эллиптического двулучепреломления $\beta_{\Sigma}^{e}$ собственных поляризационных мод, их эллиптичности $\chi_{\Sigma}$ и азимута большой оси эллипса $\alpha_{\Sigma}$ приводятся на рис. 2 и 3. Напомним, что зависимости $\beta_{\Sigma}^{e}(z)$ и $\chi_{\Sigma}(z)$ приводятся во вращающейся системе координат, а $\alpha_{\Sigma}(z)$ - в невращающейся системе координат. Рис. 2 соответствует случаю $L_{\mathrm{tw}}=2.5 \mathrm{~mm}$, рис. $3-$ случаю $L_{\mathrm{tw}}=7.5 \mathrm{~mm}$. Для ОВС c $L_{\mathrm{tw}}=2.5 \mathrm{~mm}$ численное моделирование проводилось в пределах $z=0-50 \mathrm{~mm} \mathrm{c} \mathrm{шагом} l=25 \mu \mathrm{m}$, а для ОВС с $L_{\mathrm{tw}}=7.5 \mathrm{~mm}-$ в пределах $z=0-60 \mathrm{~mm}$ с шагом $l=75 \mu \mathrm{m}$. Поскольку при одинаковом кручении spunсветоводов $L_{\mathrm{tw}}$ и различных радиусах катушки $R_{\text {coil }}$ зависимости интегральных параметров были качественно весьма похожи при незначительном количественном отличии, то мы приводим результаты только для $R_{\text {coil }}=10 \mathrm{~mm}$.

На рис. $2, a$ и $3, a$ представлены зависимости интегрального эллиптического двулучепреломления $\beta_{\Sigma}^{e}$ от длины spun-световода $z$. Видно, что величина $\beta_{\Sigma}^{e}$ при $z=0$ принимает значение порядка $\beta_{0}$ и сразу же резко снижается, а затем с небольшими квазигармоническими осцилляциями с периодом порядка $L_{b}^{\mathrm{eff}} / 2^{6}$ выходит на предельный уровень порядка $\beta_{\text {coil. }}$ Из этого следует, что кручение spun-световодов подавляет их невозмущенное линейное двулучепреломление. Из рис. 2, $a$ и 3, $a$ можно сделать вывод, что при $L_{\mathrm{tw}}=2.5 \mathrm{~mm}$ невозмущенное линейное двулучепреломление подавляется более эффективно, чем при $L_{\mathrm{tw}}=7.5 \mathrm{~mm}$. Отметим, что наши вычисления подтверждают выводы [10-23] о том, что в spun-световодах имеет место эффективное подавление невозмущенного линейного двулучепреломления. Вопрос о том, почему достаточно сильное невозмущенное линейное двулучепреломление $\beta_{0}$ практически не вносит вклада в величину $\beta_{\Sigma}^{e}$ уже при длине spun-световода всего несколько миллиметров, рассмотрим ниже.

На рис. $2, b$ и $3, b$ представлены зависимости интегральной эллиптичности $\chi_{\Sigma}(z)$ собственных поляризационных мод spun-световодов. Видно, что $\chi(0)=0$, т. е. собственные поляризационные моды на входе spunсветоводов являются линейными. С ростом $z$ зависимость $\chi_{s} \operatorname{igma}(z)$ с небольшими квазигармоническими осцилляциями с периодом порядка $L_{b}^{\text {eff }} / 2$ стремится к $\pi / 4$. Следовательно, собственные поляризационные моды spun-световодов уже при небольших длинах световода порядка нескольких миллиметров становятся практически циркулярными.

На рис. 2,c и 3,c представлены зависимости интегрального азимута большой оси эллипса $\alpha_{\Sigma}(z)$. Видно, что с ростом длины ОВС $z$ интегральный азимут меняется квазипериодически с периодом порядка $L_{b}^{\text {eff }} / 2$ по закону, близкому к пилообразному. Следует отметить, что на рис. 2 и 3 приводятся параметры только одной

\footnotetext{
${ }^{6}$ Как было отмечено выше, эти осцилляции связаны с нелинейностью дифференциального уравнения Риккати.
}

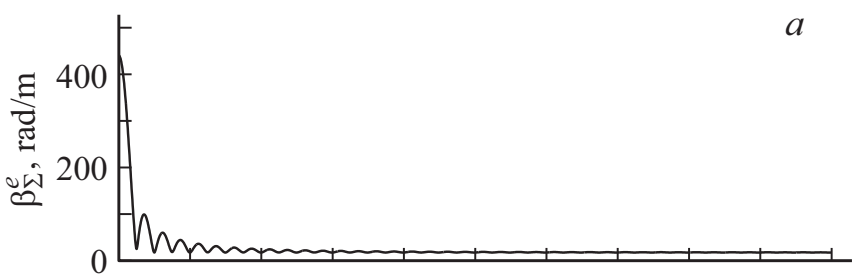

$b$

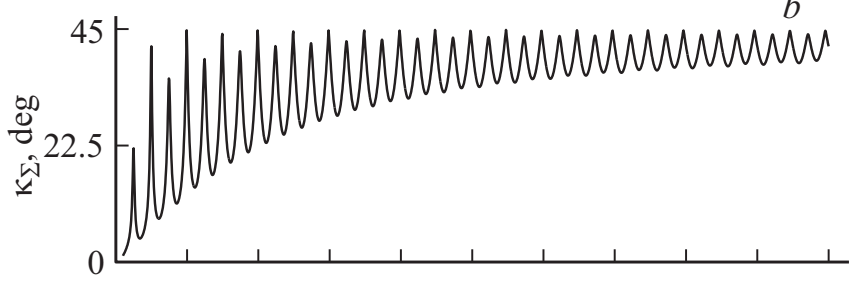

$c$

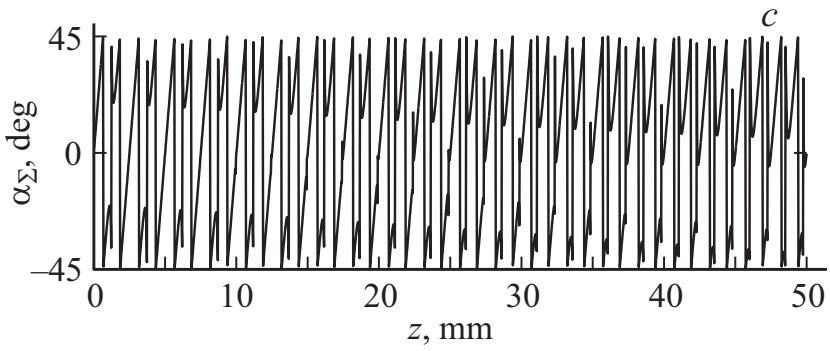

Рис. 2. Зависимости интегрального эллиптического двулучепреломления $\beta_{\Sigma}^{e}(a)$, эллиптичности $\chi_{\Sigma}(b)$ и азимута большой оси эллипса поляризации $\alpha_{\Sigma}(c)$ от длины spunсветовода $z$ с периодом кручения $L_{\mathrm{tw}}=2.5 \mathrm{~mm}$ и радиусом катушки $R_{\text {coil }}=10 \mathrm{~mm}$.
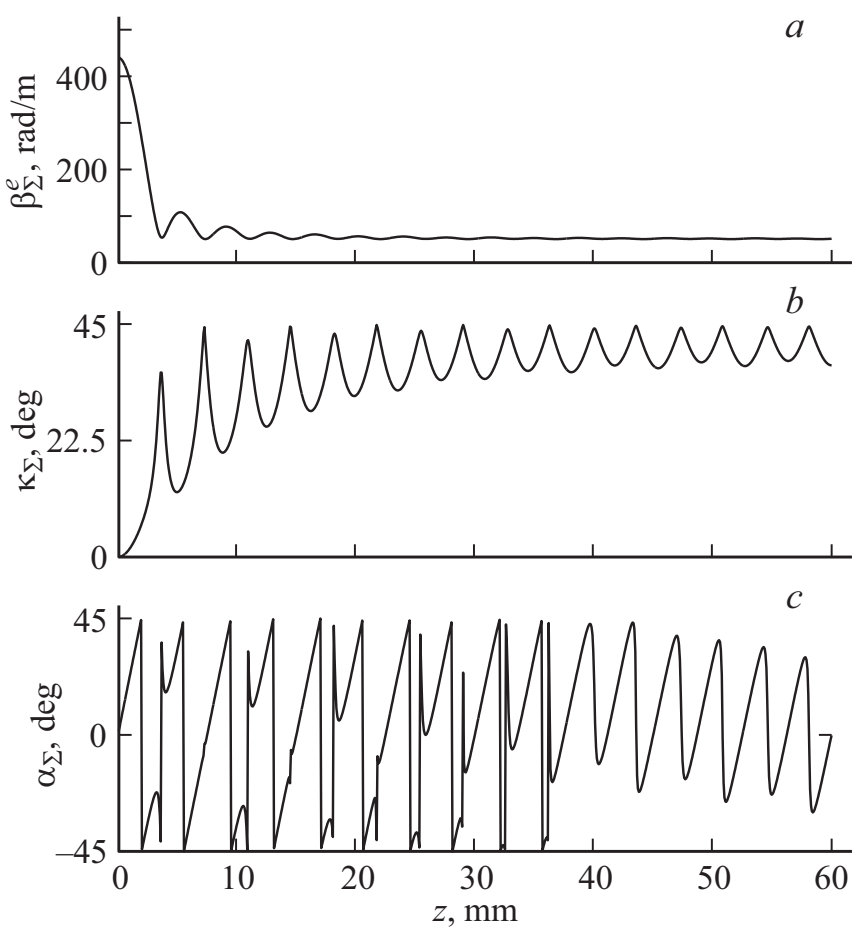

Рис. 3. Зависимости интегрального эллиптического двулучепреломления $\beta_{\Sigma}^{e}(a)$, эллиптичности $\chi_{\Sigma}(b)$ и азимута большой оси эллипса поляризации $\alpha_{\Sigma}(c)$ от длины spunсветовода $z$ с периодом кручения $L_{\mathrm{tw}}=7.5 \mathrm{~mm}$ и радиусом катушки $R_{\text {coil }}=10 \mathrm{~mm}$. 
собственной поляризационной моды, вторая поляризационная мода всегда ортогональна первой: азимут большой оси эллипса второй моды ортогонален азимуту первой моды, а направление обхода обратное.

Итак, мы получили довольно парадоксальный результат: из рис. 2 и 3 следует, что. несмотря на то что достаточно сильное невозмущенное линейное двулучепреломление spun-световодов $\beta_{0}$ существенно превышает обусловленное намоткой на катушку линейное двулучепреломление $\beta_{\text {coil }}$ (см. таблицу), невозмущенное линейное двулучепреломление $\beta_{0}$ практически не вносит вклада в величину $\beta_{\Sigma}^{e}$ уже при длине spun-световода всего несколько миллиметров. Такое поведение зависимости $\beta_{\Sigma}^{e}(z)$ протяженного отрезка spun-световода можно объяснить следующим образом. Слабое обусловленное намоткой на катушку линейное двулучепреломление spun-световода сохраняет свою ориентацию в пространстве (см. рис. 1), в то время как сильное невозмущенное линейное двулучепреломление вследствие кручения световода совершает вращение, и при этом на достаточно больших $z$ происходит его эффективное усреднение. В итоге направление слабого, обусловленного намоткой на катушку линейного двулучепреломления определяет направление азимута главной оси эллипса поляризации. ${ }^{7}$ В то же время, как было показано выше, на очень коротких отрезках spun-световодов величина $\beta_{\Sigma}^{e}$ главным образом определяется невозмущенным линейным двулучепреломлением $\beta_{0}$. Отсюда становится ясно, почему матрицу Джонса протяженного spun-световода невозможно представить в виде матрицы Джонса ВПМГ: протяженный и короткий отрезки spun-световода имеют различные механизмы формирования как линейного, так и эллиптического двулучепреломления, а также направления азимута главной оси эллипса поляризации.

На рис. 4 и 5 представлены кривые эволюции СПИ на выходе намотанного на катушку spun-световода в зависимости от длины ОВС $z$, рассчитанные по формуле (14) в невращающейся системе координат и с помощью выражения (15) отображенные на СП. Расчет проводился для всех восьми параметров spunсветоводов, приведенных в таблице. Результаты расчета показали, что кривые на СП практически не зависят от радиуса намотки spun-световода на катушку, но заметно зависят от пространственного периода его кручения. На рис. 4 приводятся кривые эволюции СПИ на СП для $L_{\mathrm{tw}}=2.5 \mathrm{~mm}$ и $R_{\text {coil }}=10 \mathrm{~mm}$ в интервале длин $z=0-360 \mathrm{~mm}$, на рис. 5 - для случая $L_{\mathrm{tw}}=7.5 \mathrm{~mm}$ и $R_{\text {coil }}=10 \mathrm{~mm}$ в интервале длин $z=0-120 \mathrm{~mm}$. Расчеты проводились для трех СПИ на входе spun-световода: $S_{1}=1, S_{2}=1$ и $S_{3}=1$ (см. выражение (15)).

Из рис. 4 и 5 видно, что для $S_{1}=1$ (горизонтальная линейная поляризация излучения на входе) кривая эволюции СПИ представляет собой фигуру, подобную циклоиде, расположенной выше экватора СП, для $S_{2}=1$

\footnotetext{
7 Такое объяснение сохранения ориентации азимута главной оси эллипса поляризации spun-световодов было предложено Вл.В. Кочаровским.
}

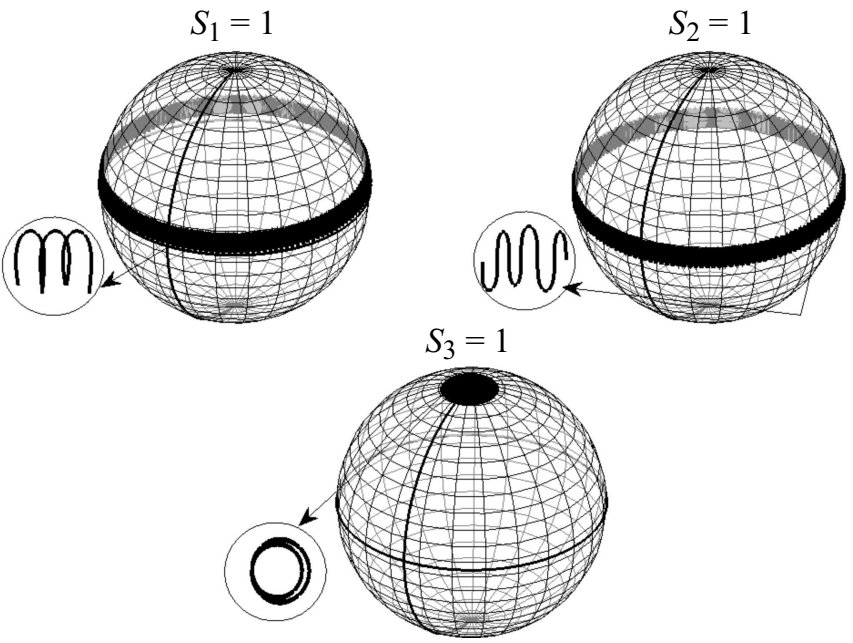

Рис. 4. Отображение на СП эволюции состояния поляризации излучения в намотанном на катушку spun-световоде с периодом кручения $L_{\mathrm{tw}}=2.5 \mathrm{~mm}$ и радиусом катушки $R_{\text {coil }}=10 \mathrm{~mm}$ для различных поляризаций излучения на входе волокна: $S_{1}=1, S_{2}=1, S_{3}=1$. В небольших кружках показаны увеличенные кривые эволюции СПИ на СП для $z=0-5 \mathrm{~mm}$.
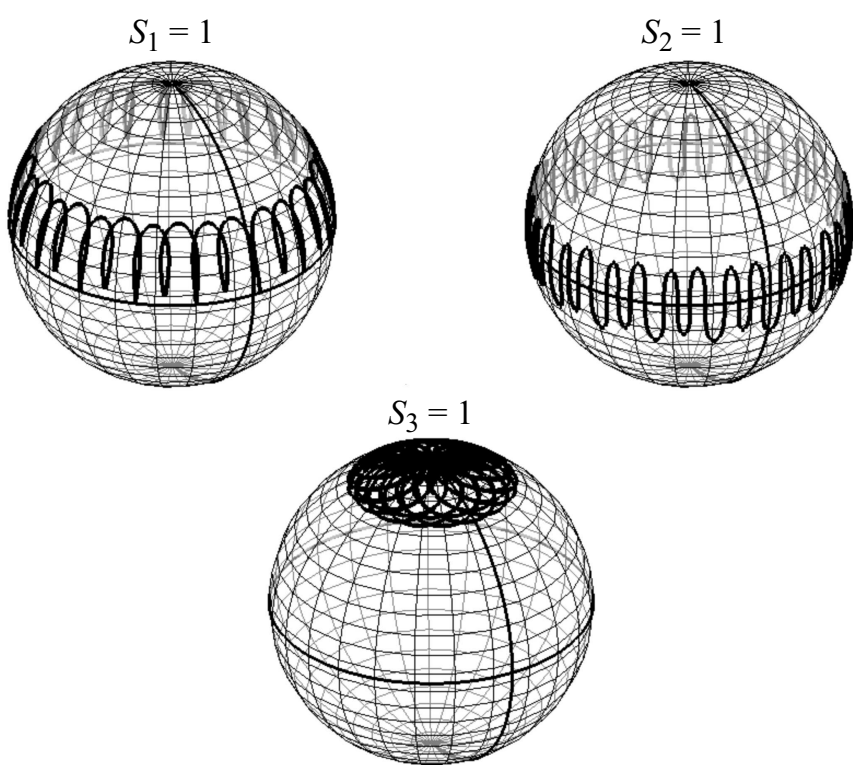

Рис. 5. Отображение на СП эволюции состояния поляризации излучения в намотанном на катушку spun-световоде с периодом кручения $L_{\mathrm{tw}}=7.5 \mathrm{~mm}$ и радиусом катушки $R_{\text {coil }}=10 \mathrm{~mm}$ для различных поляризаций излучения на входе волокна: $S_{1}=1, S_{2}=1, S_{3}=1$.

(линейная поляризация под углом 45) - фигуру, подобную синусоиде, расположенную на экваторе СП, для $S_{3}=1$ (круговая поляризация) - сложную фигуру, напоминающую раскручивающуюся спираль, расположенную в области Северного полюса СП. Отметим, что на рис. 4 кривые похожи на те, что на рис. 5, но имеют более мелкий масштаб. Вследствие этого на рис. 4 для 
всех трех случаев СПИ на входе волокна в небольших кружках показаны увеличенные кривые эволюции СПИ на СП для $z=0-5 \mathrm{~mm}$.

Отметим, что для эволюции СПИ в скрученных ОВС с невозмущенным линейным двулучепреломлением фигура на СП, подобная циклоиде, ранее была рассмотрена в работе [4], фигура, подобная синусоиде - в работе [22], а фигура, напоминающая раскручивающуюся спираль в работе [14]. Фигура, подобная циклоиде, вероятно, рассматривалась также в работе [20], однако результаты расчетов [20] приводятся не на СП, а на так называемой комплексной плоскости, что отчасти затрудняет сравнение результатов. В работе [4] рассматривается фигура на СП, являющаяся набором концентрических окружностей, что довольно близко к раскручивающейся спирали.

\section{7. Заключение}

Сформулируем основные результаты работы.

1. Показано что для скрученных оптических сред циркулярное двулучепреломление имеет место не только при наличии исходного линейного двулучепреломления, но и при ненулевом значении коэффициента фотоупругости даже при отсутствии исходного линейного двулучепреломления.

2. Показано, что значения циркулярного двулучепреломления скрученных ОВС в невращающейся и в сопровождающей кручение винтовой системах координат существенно отличаются.

3. Показано, что матрица Джонса скрученного и намотанного на катушку ОВС может быть представлена в виде матрицы Джонса ВПМГ только локально, для очень короткого отрезка ОВС, длина которого на несколько порядков меньше длины поляризационных биений. Для протяженного отрезка такого ОВС данное представление невозможно.

4. Показано, что суммирование векторов $\mathfrak{B}_{\text {coil }}$ и $\mathfrak{B}_{0}$ происходит в реальном пространстве, в плоскости, ортогональной оптической оси ОВС, а в системе координат $X^{\prime \prime} Y^{\prime \prime}$, в которой вектор $\mathfrak{B}_{\text {lin }}$ совпадает с осью $X^{\prime \prime}$, тензор диэлектрической проницаемости для суммарного линейного двулучепреломления намотанного на катушку spun-световода принимает диагональный вид.

5. Показано, что сильное невозмущенное линейное двулучепреломление spun-световодов эффективно подавляется при их намотке на катушку. При этом величина $\beta_{\Sigma}^{e}$ асимптотически стремится к величине слабого линейного двулучепреломления, связанного с изгибом световода при намотке на катушку.

6. Показано, что интегральное эллиптическое двулучепреломление собственных поляризационных мод протяженного отрезка spun-световода асимптотически стремится к циркулярному.

7. Показано, что в процессе линейной трансформации поляризационных мод возникают поляризацион- ные явления, приводящие к небольшим квазигармоническим осцилляциям параметров двулучепреломления spun-световодов в зависимости от их длины с периодом порядка половины эффективного периода поляризационных биений. Это явление имеет некоторую аналогию с эффектом Коттона-Мутона.

Авторы выражают благодарность И.С. Емельяновой, Вл.В. Кочаровскому, Э. Лефевру и С.К. Моршневу за обсуждение рассматриваемой задачи, В.М. Геликонову за ряд полезных замечаний, позволивших существенно улучшить изложение результатов работы, П.А. Шилягину за помощь в работе. Работа поддержана проектами по Государственному заданию № 0035-2014-0018 и 00362014-0002, а также частично грантом совета при президенте РФ по поддержке ведущих научных школ № НШ8489.2016.2.2.

\section{Список литературы}

[1] Железняков В.В., Кочаровский В.В., Кочаровский Вл.В. // УФН 1983. Т. 141. № 2. С. 257.

[2] Кочаровский Вл.В. Автореферат канд. дис. Горький: ИПФ PAH, 1985.

[3] Кочаровский В.В., Кочаровский Вл.В. Линейное взаимодействие волн. Физическая энциклопедия. М.: Сов. Энциклопедия. 1990. Т. 2. С. 584.

[4] Ulrich R., Simon A. // Appl. Opt. 1979. V. 18. N 13. P. 2241.

[5] Monerie M., Jeunhomme L. // Opt. Quantum Electron. 1980. V. 12. N 6. P. 449.

[6] Kaminov I.P. // IEEE J. Quant. Electron. 1981. V. QE-17. N 1. P. 15.

[7] Малыкин Г.Б., Позднякова В.И., Шерешевский И.А. // Опт. и спектр. 1997. Т. 83. № 5. С. 843.

[8] Малыкин Г.Б., Позднякова В.И. Поляризационные эффекты в кольцевых интерферометрах. Нижний Новгород: ИПФ РАН, 2008. 208 c.

[9] Malykin G.B., Pozdnyakova V.I. Ring interferometry. Berlin: De Gruyter, 2013. 320 p.

[10] Barlow A.J., Ramskov-Hansen J.J., Payne D.N. // Appl. Opt. 1981. V. 20. N 17. P. 2962.

[11] Payne D.N., Barlow A.J., Ramskov-Hansen J.J. // J. Quant. Electron. 1982. V. QE-18, N 4. P. 477.

[12] Payne D.N., Barlow A.J., Ramskov-Hansen J.J. // IEEE Trans. On Microvawe Theory and Techniques. 1982. V.MTT-30, N 4. P. 323.

[13] Day G.W., Payne D.N., Barlow A.J., Ramskov-Hansen J.J. // Opt. Lett. 1982. V. 7. N 5. P. 238.

[14] Day G.W., Payne D.N., Barlow A.J., Ramskov-Hansen J.J. // J. Lightwave Techn. 1984. V. LT-2. N 1. P. 56.

[15] Laming R.I., Payne D.N. // J. Lightwave Techn. 1989. V. 7. N 12. P. 2084.

[16] Губин В.П., Исаев В.А., Моршнев С.К., Сазонов А.И., Старостин Н.И., Чаморовский Ю.К., Усов А.И. // Квант. электрон. 2006. Т. 36. № 3. С. 287.

[17] Gubin V.P., Isaev V.A., Morshnev S.K., Sazonov A.I., Starostin N.I., Chamorovsky Yu.K., Oussov A.I., Otrokhov S.Yu. // Proc. SPIE. 2006. V. 6251. P. OP-1.

[18] Morshnev S.K., Ryabko M.V., Ghamorovskii Y.K // Proc. SPIE. 2007. V. 6594. P. 6594OR. 
[19] Губин В.П., Моршнев С.К., Старостин Н.И., Сазонов А.И., Чаморовский Ю.К., Исаев В.А // Радиотехника и электроника. 2008. Т. 53. № 8. С. 971.

[20] Моршнев С.К., Губин В.П., Воробьев И.Л., Старостин Н.И., Сазонов А.И., Чаморовский Ю.К., Коротков Н.М. // Квант. электрон. 2009. Т. 39. № 3. С. 287.

[21] Чаморовский Ю.К., Старостин Н.И., Моршнев С.К., Губин В.П., Рябко М.В., Сазонов А.И., Воробьев И.Л. // Квант. электрон. 2009. Т. 39. № 11. С. 1074.

[22] Моршнев С.К., Губин В.П., Пржиялковский Я.В., Старостин Н.И. // Квант. электрон. 2013. Т. 43. № 12. С. 1143.

[23] Пржиялковский Я.В., Моршнев С.К., Старостин Н.И., Губин В.П. // Квант. электрон. 2014. Т. 44. № 10. С. 957.

[24] Weng J., Liu W., Huang Y., Liu Y., Luo Y., Peng G.-D., Pang F., Chen Z., Wang T. // J. Lightwave Techn. 2015. V. 33. N 12. P. 2674.

[25] Малыкин Г.Б, Позднякова В.И // Изв. вузов Радиофизика. 2011. T. 54. № 4. C. 302.

[26] Малыкин Г.Б,. Позднякова В.И, Шабанов Д.В. // Изв. вузов Радиофизика. 2012. Т. 55. № 12. С. 792.

[27] Beravat R., Wong G.K.L., Xi X.M., Frosz M.H., Russel P.St.J. // Opt. Lett. 2016. V. 41. N 7. P. 1672.

[28] Optical Fiber sensors: principles and components. V. 1 / Ed. by Culshaw B., Daikin J./ Boston-London: Artech House. 1988. Перевод: Оптоволоконные сенсоры. Вып. 1. Принципы и компоненты. Ред. Дейкин Дж., Калшо Б./ М.: Мир, 1992. $438 \mathrm{c}$.

[29] Shurkliff W.A. Polarized light. Cambridge, Massachusets: Harvard Univ. Press., 1962. 207 p. (Перевод: Шерклифф У. Поляризованный свет. М.: Мир, 1965. 264 с.)

[30] Малыкин Г.Б. // Изв. вузов. Радиофизика. 1997. Т. 40. № 3. C. 265.

[31] Малыкин Г.Б., Позднякова В.И. // УФН. 2004. Т. 174. № 3. C. 303.

[32] Малыкин Г.Б., Позднякова В.И. // Опт. и спектр. 2017. T. 122. № 1. C. 153.

[33] Малыкин Г.Б. // УФН. 2016. Т. 186. № 12. С. 1355.

[34] Малыкин Г.Б., Позднякова В.И., Шерешевский И.А. // Опт. и спектр. 2000. Т. 88. В. 3. С. 477.

[35] Гинзбург В.Л. // ЖТФ 1944. Т. 14. № 3. С. 181.

[36] Tabor W.J., Chen F.S. // J. Appl. Phys. 1969. V. 40. N 7. P. 2760.

[37] Namihira Y., Kudo M., Mushiake Y. // Electron. and Commun. Jap. 1977. V. 60-C. N 7. P. 107.

[38] Ulrich R., Rashleigh S.C., Eickhoff W. // Opt. Lett. 1980. V. 5. N 6. P. 273.

[39] Rashleigh S.C., Ulrich R. // Opt. Lett. 1980. V. 5. N 8. P. 354.

[40] Lefevre H.C. // Electron. Lett. 1980. V. 16. N 20. P. 778.

[41] Ulrich R. // Fiber-optics rotation sensors /Ed. by Ezekiel S., Arditty H.J. Berlin: Springer Verlag, 1982. p. 52

[42] Lefevre $H$. The fiber-optic gyroscope. Boston-London: Artech House, 2014. 409 p.

[43] Lefevre H. // Fiber-optics rotation sensors /Ed. by Ezekiel S., Arditty H.J. Berlin: Springer Verlag, 1982. P. 136

[44] Johnson M. // Appl. Opt. 1979. V. 18. N 9. P. 1288.

[45] Aulich A., Beck W., Douklias N., Harms H., Papp A., Shneider H. // Appl. Opt. 1980. V. 19. N 22. P. 3735.

[46] Stolen R.H., Pleibel W., Simpson J.R. // J.Lightwave Techn. 1984. V. LT-2. N 5. P. 639.

[47] Okamoto K., Hosaka T., Noda J. // J. Lightwave Techn. 1985. V. LT-3. N 4. P. 758.
[48] Бычков А.В., Гусовский Д.Д., Дианов Е.М., Зайцев Ю.И., Кофанов С.В., Малыкин Г.Б., Смирнов О.Б., Степанов Д.П., Хрулев В.П. // Тезисы V Всес. конф. 'Волоконнооптические системы передачи’ (ВОСП-88). 1988. С. 42.

[49] Арутюнян 3.Э., Грудинин А.Б., Гурьянов А.Н., Гусовский Д.Д., Дианов Е.М., Зайщев Ю.И., Игнатьев С.В., Малыкин Г.Б., Смирнов О.Б., Степанов Д.П. // Тезисы V Всес. конф. „Волоконно-оптические системы передачи“ (ВОСП-88). 1988. C. 7.

[50] Shute M.W., Brown C.S. // J. Lightwave Techn. 1989. V. 7. N 12. P. 2013.

[51] Арутюнян 3.Э., Грудинин А.Б., Гурьянов А.Н., Гусовский Д.Д., Дианов Е.Н., Игнатьев С.В., Смирнов О.Б. // Квант. электрон. 1990. Т. 17, № 10. С. 1363.

[52] Dianov E.M., Grudinin A.B., Gurjanov A.N., Gusovsky D.D., Harutjunian Z.E., Ignatjev S.V., Smirnov O.B. // J. Lightwave Techn. 1992. V. 10. N 2. P. 118.

[53] Якубович Е.И., Малыкин Г.Б. // Изв. вузов. Радиофизика. 2002. T. 45. № 11. С. 975.

[54] Виницкий С.И., Дербов В.Л., Дубовик В.М., Марковски Б.Л., Степановский Ю.П. // УФН. 1990. Т. 160. В. 6. C. 1 .

[55] Рытов С.М. // ДАН СССР. 1938. Т. 18. № 4-5. С. 263.

[56] Рытов С.М. // Труды физического института. М.-Л.: Изд. AH CCCP. 1940. T. 2. B. 1. C. 41.

[57] Rashleigh S.C., Ulrich R.S. // Opt. Lett. 1978. V. 3. N 2. P. 60.

[58] Yariv A., Yeh P. Optical waves in crystals. NY. Chichester; Brisbane; Toronto; Singapore: John Wiley \& Sons, 1983. Перевод: Ярив А., Юх П. Оптические волны в кристаллах. М.: Мир, 1987. 616 c.

[59] Sasaki Y., Hosaka T., Noda J. // J. Lightwave Techn. 1984. V. LT-2. N 6. P. 816.

[60] Rashleigh S.C., Ulrich R. // Appl. Phys. Lett. 1979. V. 34. N 11. P. 768.

[61] Моршнев С.К. Автореферат докт. дис. Фрязино: ИРЭ РАН, 2008.

[62] Azzam R., Bashara N. Ellipsometry and Polarized light. Amsterdam; NY.; Oxford: North-Holland Publ. Comp., 1977. Перевод: Аззам Р., Башара Н. Эллипсометрия и поляризованный свет. М.: Мир, 1981. 583 с.

[63] Смоленский Г.А. Физика магнитных диэлектриков. Л.: Наука, 1974. 454 c. 